\title{
Eggshell as a carbon dioxide sorbent: Kinetics of the calcination and carbonation reactions
}

Shakirudeen A. Salaudeen ${ }^{\mathrm{a}}$, S.M. Al-Salem ${ }^{\mathrm{b}}$, Mohammad Heidari $^{\mathrm{a}}$, Bishnu Acharya ${ }^{\mathrm{c}}$, Animesh Dutta ${ }^{\mathrm{a}, *}$

${ }^{a}$ Mechanical Engineering Program, School of Engineering, University of Guelph, Guelph, Ontario N1G 2W1, Canada.

${ }^{\mathrm{b}}$ Environment \& Life Sciences Research Centre, Kuwait Institute for Scientific Research (KISR), P.O. Box 24885, Safat 13109, Kuwait.

c School of Sustainable Design Engineering, University of Prince Edward Island, 550 University Avenue, Charlottetown, PEI C1A 4P3, Canada.

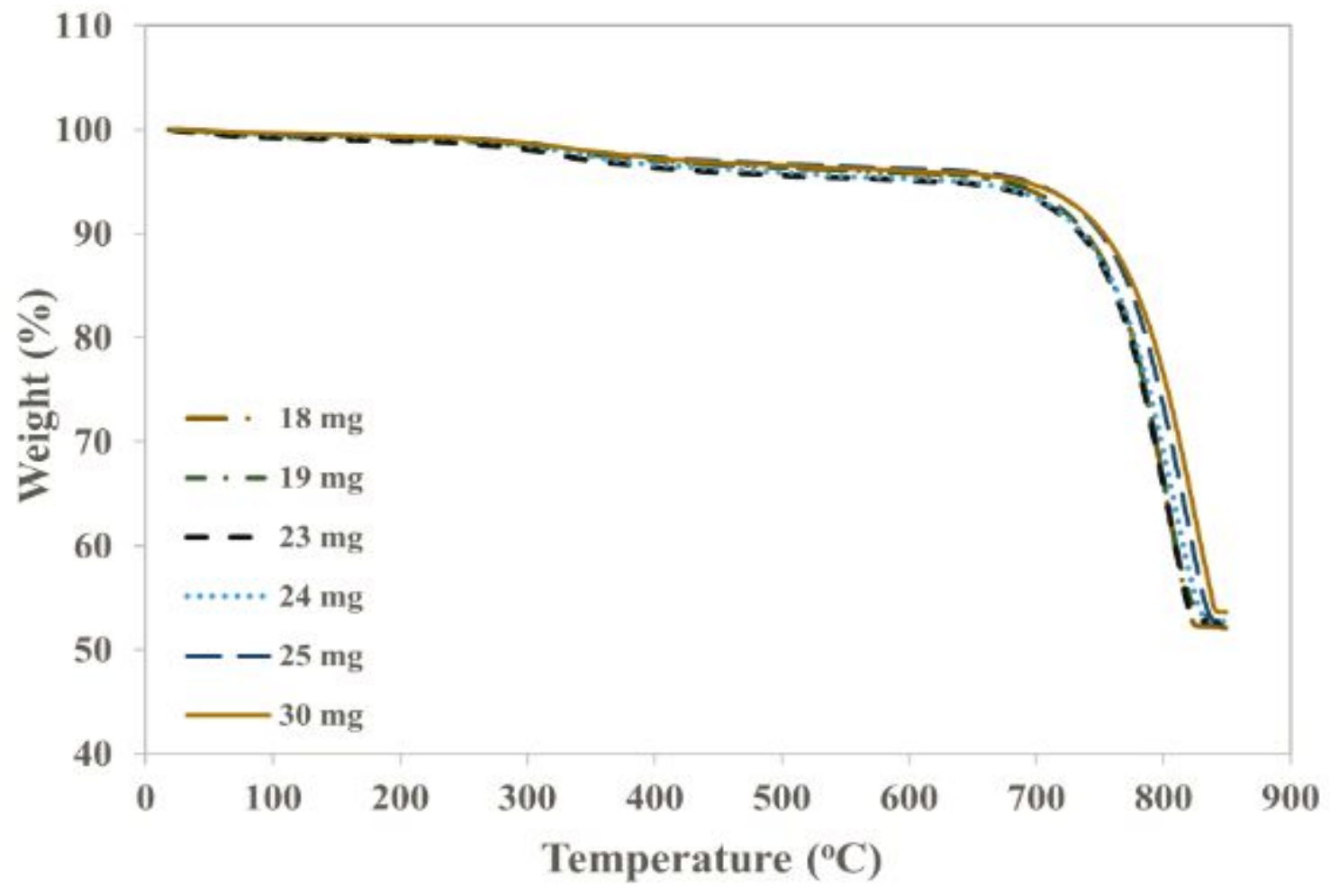

Figure S1. TG curves for the mass independence test. 